\title{
COBISS U MAKEDONIJI: OSVRT POVODOM DVA JUBILEJA
}

\author{
mr. Žaklina Gjalevska, bibliotekar-savjetnik, VBM Centar / Librarian Advisor, VBM Center \\ NU Nacionalna i univerzitetska biblioteka "Sv. Kliment Ohridski" - Skopje, Makedonija \\ National and University Library „St. Kliment Ohridski“ - Skopje, Macedonia \\ zaklina@nubsk.edu.mk
}

\begin{abstract}
Sažetak
Ovaj rad daje kratak pregled primjene organizacionog modela i programske opreme COBISS u razvoju nacionalnog bibliotečno-informacijskog sistema u Makedoniji u proteklih 30 godina. Počeci primjene COBISS-a vode još od 1989. u okviru sistema uzajamne katalogizacije u projektu SNTIJ/BIS. Nakon raspada Jugoslavije i prestanka funkcioniranja sistema uzajamne katalogizacije, zbog potrebe uvođenja novih tehnologija i automatizacija svojih procesa nekoliko makedonskih biblioteka su ponovo počele da koriste programsku opremu COBISS. U 2004. godini, kada je veći broj biblioteka projavilo interes za primjenu programske opreme COBISS, Ministarstvo kulture RM je odlučilo da se platforma COBISS primijeni za razvoj nacionalnog bibliotečko-informacionog sistema Makedonije, i za tu svrhu je u Nacionalnoj i univerzitetskoj biblioteki "Sv. Kliment Ohridski" bio osnovan centar Virtuelne biblioteke Makedonije tj. VBM Centar. U proteklih 15 godina sistem COBISS.MK funkcionira i razvija se prema razvojnim planovima mreže COBISS. Net. Do kraja ove jubilarne godine u njemu biće uključeno više od 70 biblioteka (nacionalna, javne, visokoškolske i specijalne). Višedecenijska primjena COBISS'-a omogućila je vidljivost biblioteka na mreži, zaštedu i racionalizaciju vremena u procesu obrade bibliotečkog fonda, te animiranje javnosti u povećanju interesa za korištenje biblioteka.
\end{abstract}

Ključne riječi: COBISS.MK, VBM Centar, nacionalni bibliotečno-informacijski sistem Makedonije, automatizacija biblioteka, COBISS.Net, E-CRIS.MK

\section{Uvod}

Godina 2019. objedinila je dvije značajne godišnjice povezane s primjenom platforme i programske opreme COBISS u Makedoniji. Naime, ove godine navršava se 30 godina kako se COBISS kao programska oprema koristi u tekućem poslovanju i automatizaciji makedonskih biblioteka. Ujedno, navršava se i 15 godina otkako je potpisan ugovor za implementaciju COBISS-a kao organizacionog modela za izgradnju nacionalnog bibliotečko-informacijskog sistema u Makedoniji i od osnivanja nacionalnog COBISS centra.

Svaki je jubilej povod za retrospektivu događaja i postignuća u periodu koji se obilježava, posebno kada se bilježi godišnjica uvođenja nove ideje, modela, proizvoda, kao što je to COBISS, koji svojim postojanjem, funkcionisanjem i primjenom utiče na razvoj djelatnosti u kojoj se primjenjuje, te na razvoj društva uopšte. Povodom ova dva jubileja, u produžetku dajemo kratki prikaz i retrospektivu događaja.

\section{Počeci COBISS-a}

Priča o COBISS-u u Makedoniji počinje identično kao i u ostalim zemljama bivše Jugoslavije. U okviru sistema uzajamne katalogizacije, koji je predstavljao osnovu bibliotečko-informacionog sistema i sistema naučnih i tehnoloških informacija Jugoslavije SNTIJ/BIS, Makedonija je uzela aktivno učešće i uključila se sa 4 biblioteke: Nacionalna i univerzitetska biblioteka "Sv. Kliment Ohridski" - Skopje, Univerzitetska biblioteka "Sv. Kliment Ohridski" - Bitola, Prirodno-matematički fakultet u Skopju i Kinoteka Makedonije. Pripremne aktivnosti odvijale su se tokom druge polovine 1988. godine, a sa radom se počelo u početku 1989. godine. 
Nažalost, raspad Jugoslavije 1991. godine doveo je do prestanka funkcionisanja sistema uzajamne katalogizacije. Neke od uključenih biblioteka produžile su koristiti tadašnju verziju COBISS-a na lokalnom nivou, dok su ostale prekinule s automatizovanom obradom građe.

Nakon osamostaljenja, na osnovi iskustva iz projekta SNTIJ/BIS, započete su aktivnosti na projektu za razvoj sistema naučnih i tehnoloških informacija Makedonije i bibliotečko-informacionog sistema (SNTIM/BIS). Projekt je podržalo Ministarstvo nauke RM, a nosioci projekta su bili Nacionalna i univerzitetska biblioteka "Sv. Kliment Ohridski" Skopje i Prirodno-matematički fakultet u Skopju. Međutim, rad na ovom projektu nije išao očekivanom brzinom, tako da su biblioteke počele da samostalno traže rješenja koja bi im pomogla u realizaciji ove potrebe.

Tokom 1996. godine Nacionalna i univerzitetska biblioteka "Sv. Kliment Ohridski" - Skopje, Univerzitetska biblioteka "Sv. Kliment Ohridski" - Bitola i Prirodno-matematički fakultet u Skopju obnovili su saradnju sa IZUM-om i potpisali ugovore za instalaciju nove verzije programske opreme COBISS. Međutim, ove tri biblioteke su i dalje radile izolovano u svojim lokalnim bazama, koje tada nisu bile međusobno povezane. Situacija se promijenila 2002. godine, kada je i Makedonska akademija nauka i umjetnosti odlučila da koristi programsku opremu COBISS za automatizaciju poslovanja svoje biblioteke. Tada je urađeno međusobno povezivanje lokalnih baza sve 4 biblioteke i uspostavljena je uzajamna baza podataka COBIB.MK, koja je u tom trenutku brojala 248.077 bibliografskih zapisa.

Sljedeće, 2003. godine priključile su se još tri biblioteke: Univerzitetska biblioteka "Goce Delčev" iz Štipa, Opštinska matična biblioteka "Blagoj Jankov - Mučeto" i Gradska biblioteka "Braća Miladinovci” iz Skopja, čime je sistem COBISS.MK polako, ali sigurno, počeo da raste.

\section{COBISS.MK kao nacionalni bibliotečko- informacioni sistem Makedonije}

Veliki preokret u razvoju sistema COBISS.MK dogodio se 2004. godine. Te je godine Ministarstvo kulture Republike Makedonije odobrilo 2 projekta za automatizaciju javnih biblioteka iz istočnog i zapadnog regiona Makedonije primjenom programske opreme COBISS, Univerzitetske biblioteke "Goce Delčev" iz Štipa i Univerzitetske biblioteke "Sv. Kliment Ohridski" iz Bitole, koje su u tom periodu imale funkciju matičnih biblioteka za istočni, odnosno zapadni region Makedonije. Projekti su bili planirani da se realizuju u nekoliko faza i obuhvaćali su ukupno 20 javnih biblioteka (u prvoj fazi 12, a u drugim preostale javne biblioteke).
Podrška koju je Ministarstvo kulture dalo ovim projektima za automatizaciju poslovanja biblioteka pod njegovom nadležnošću i time izgradnju nacionalnog bibliotečko-informacionog sistema na podlozi platforme COBISS bio je pozitivan signal i ključni faktor da se 3. decembra 2004. godine i oficijelno potpiše sporazum između Nacionalne i univerzitetske biblioteke "Sv. Kliment Ohridski" - Skopje i IZUM-a za uspostavljanje bibliotečko-informacionog sistema COBISS.MK. U okviru biblioteke formiran je VBM Centar kao bibliotečko-informacioni servis sistema, a preduzet je i niz aktivnosti za poboljšanje kompjuterske i komunikacijske opreme Nacionalne biblioteke, kao i opremljivanje centra za obrazovanje korisnika COBISS-a.

Realizaciji gorepomenutih projekata priključili su se i Pedagoški fakultet u Bitoli, Tehnološko-metalurški fakultet iz Skopja i biblioteka Državnog zavoda za statistiku, tako da je, kada se oficijelno ustanovio, nacionalni bibliotečko-informacioni sistem COBISS.MK brojao 21 članicu.

\section{Funkcionisanje u okviru mreže COBISS.Net}

Uspostavljanje i funkcionisanje mreže COBISS. Net, čime su članicama COBISS.MK bili omogućeni pristup i razmjena zapisa iz uzajamnih baza podataka drugih sistema COBISS, predstavljalo je dodatno olakšanje i pomoć bibliotekama u procesu obrade bibliotečke građe. Prema statistikama, u bazama biblioteka $75 \%$ zapisa su zapisi koji su preuzeti iz drugih biblioteka u mreži COBISS.Net, a samo $25 \%$ zapisa kreirala je sama biblioteka. Kod određenih vrsta biblioteka (kao što su manje javne biblioteke), ovaj procenat je i veći, i do $100 \%$ preuzetih zapisa.

Realizacija II faze projekta COBISS.Net, koji je podržalo i Ministarstvo obrazovanja i nauke Makedonije, i aktivnosti koje su bile njime obuhvaćene, pridonijeli su daljem razvoju sistema i proširivanju novim bibliotekama, prvenstveno visokoškolskim i specijalizovanim, čime su se podigli kvalitet i brojnost članica, koja je iznosila 42 biblioteke. Projekat je bio značajan i za podizanje stručne osposobljenosti bibliotekara, jer su u okviru projekta bile planirane i realizovane diplomske studije bibliotekarstva, $\mathrm{u}$ dva ciklusa, za 15 bibliotekara iz Makedonije, koji su stekli stručno zvanje magistra bibliotekarstva.

Broj članica sistema COBISS.MK ostao je nepromijenjen sve do 2018. godine, kada je IZUM dao specijalnu ponudu povodom 30 . godina postojanja COBISS-a. Ova je ponuda pobudila veliko interesovanje kod biblioteka i samog Ministarstva kulture, koje je preporučilo institucijama u svojoj nadležnosti da iskoriste ovu ponudu i da se uključe u sistem COBISS.MK. Tako se, na osnovu ove ponude, u posljednje dvije godine broj članica povećao za $50 \%$ i 
trenutno iznosi 63 članice, a vodi se postupak uključivanja još 10 institucija, tako da do kraja godine očekujemo da broj članica iznosi ukupno 73.

Struktura sistema COBISS.MK prema vrstama biblioteke je sljedeća:

$\begin{array}{lcc}\text { Vrsta biblioteke } & \begin{array}{l}\text { Trenutan broj } \\ \text { članica }\end{array} & \begin{array}{c}\text { Očekivani broj } \\ \text { do kraja } 2019 .\end{array} \\ \text { Nacionalna } & 1 & 1 \\ \text { Javne biblioteke } & 33 & 33 \\ \text { Visokoškolske/univerzitetske } & 13 & 14 \\ \text { Specijalizovane } & 16 & 20 \\ \text { Školske } & 0 & 5\end{array}$

Uzajamna baza podataka COBIB.MK sadrži više od 620.000 zapisa, dok je ukupan broj zapisa u lokalnim bazama podataka sistema više od 1.100 .000 zapisa.

Sve su biblioteke potpuno prešle na rad na platformi COBISS3 početkom jula 2017. godine. Od njih, pored segmenta COBISS3/Fond, 15 biblioteka koriste segment COBISS3/Katalogizacija, 17 koristi segment COBISS3/Pozajmica, a 2 segment COBISS3/Nabavka.

Informacioni sistem za naučnoistraživačku djelatnost E-CRIS.MK, koji je bio implementiran u okviru II faze projekta COBISS.Net, sadrži podatke o više od 3000 naučnih radnika, 175 naučnoistraživačkih ustanova i 545 istraživačkih odjeljenja.

Tokom svih ovih godina, u cilju funkcionisanja kao dio COBISS.Net-a, VBM Centar je uložio sve napore i preduzeo sve neophodne aktivnosti za pravilno i nesmetano funkcioniranje i razvoj sistema COBISS.MK te blagovremeno implementiranje svih noviteta i novih verzija programske opreme COBISS. Trebamo naglasiti da smo to postigli uz veliku pomoć i podršku IZUM-a, u obliku stručne pomoći, obrazovanja stručnog osoblja, kao i pomoći kod obezbjeđenja potrebne IKT opreme za funkcionisanje sistema COBISS.MK.

\section{Obrazovanje u sistemu COBISS}

Jedan od osnovnih preduslova za pravilno funkcionisanje i kvalitet sistema COBISS jeste kontinuirano obrazovanje korisnika sistema COBISS. Stoga je u cijelom periodu primjene COBISS-a, a naročito u periodu nakon implementacije COBISS-a kao nacionalnog bibliotečko-informacionog sistema, dužna pažnja bila posvećivana obrazovanju saradnika kako iz biblioteka članica tako i iz VBM Centra.

U proteklih 15 godina VBM Centar je za korisnike COBISS-a organizovao i održao 98 kurseva na kojima je učestvovalo 989 učesnika. Za platformu COBISS2 održano je 47, a za platformu COBISS3 51 kurs. Kao posebno aktivne godine na ovom polju izdvajamo 2006. i 2013. godinu, kada je VBM Cen- tar organizovao 15, odnosno 20 kurseva. U 2006. su bile organizovane obuke za saradnike iz biblioteka koje su se uključile na osnovu projekta COBISS. Net - II faza, kada je učestvovalo 144 saradnika, dok je 2013. bila godina kada su sve biblioteke, nakon nacionalne, započele sa prelaskom na prvi segment iz platforme COBISS3, segment COBISS3/ Fond. Tada je na kursevima učestvovalo ukupno 199 učesnika.

Za sve kurseve koje je organizovao za potrebe članica sistema COBISS, VBM Centar se trudio da obezbijedi da naši saradnici steknu licence za predavača. Tako za sadašnju platformu COBISS3 VBM Centar ima licencirane predavače za sljedeće kurseve:

- COBISS3/Preuzimanje zapisa i fond

- COBISS3/Fond - serijske publikacije

- COBISS3/Katalogizacija - početni kurs

- COBISS3/Katalogizacija - napredni kurs

- COBISS3/Pozajmica

- COBISS3/Nabava - monografske publikacije

Sticanje licenci za uzajamnu katalogizaciju regulisano je Pravilnikom za sticanje dozvola za uzajamnu katalogizaciju, koji uređuje propisani postupak koji se primjenjuje u COBISS.Net-u. Prema ovim pravilima do sada su dodijeljene sljedeće licence:

- licenca A - 72 katalogizatora,

- licenca B1 - 16 katalogizatora,

- licenca B2 - 11 katalogizatora,

- licenca C - 40 katalogizatora,

- licenca D - 11 katalogizatora.

Na osnovu Pravilnika VBM Centar sprovodi i periodičnu kontrolu kvaliteta zapisa katalogizatora, sa ciljem da se održi i poboljša kvalitet baza podataka u sistemu COBISS.MK.

\section{Obilježavanje jubileja 30. godina COBISS}

Da se radi o značajnom jubileju za bibliotečku djelatnost u Makedoniji pokazuje i činjenica da je sredinom oktobra ove godine, na 46. godišnjem sastanku Bibliotekarskog društva Makedonije, u okviru kojeg se održala i Međunarodna stručno-naučna konferencija bibliotekara, jedna od tema konferencije bila " 30 godina COBISS-a u Makedoniji - benefiti i značaj za razvoj biblioteke i bibliotečke djelatnosti". Na konferenciji je gostovao i direktor IZUM-a dr. Aleš Bošnjak, koji se prigodno obratio i otvorio ovu sesiju konferencije, kao i saradnici mr. Sergej Lah, koji je prezentirao novitete koje donosi COBISS + u poređenju sa COBISS/OPAC-om, i Nataša Murković, koja je prezentirala demo verziju mobilne aplikacije mCOBISS za Makedoniju, koja se treba implementirati do kraja ove godine. $\mathrm{Na}$ ovoj sesiji učestvovalo je sa svojim izlaganjima i više saradnika iz Makedonije, Srbije i Crne 
Gore, koji su prenijeli informacije, svoja iskustva u primjeni i radu u COBISS-u. Konferenciji je prisustvovalo 160 učesnika iz Makedonije, Srbije, Crne Gore, Slovenije i Turske, tako da je bila odlična mogućnost razmjene informacija, iskustava i pitanja o bibliotečkoj djelatnosti i primjeni COBISS-a.

\section{Umjesto zaključka}

Benefiti od primjene COBISS-a u svakodnevnom poslovanju biblioteka zaista su veliki i značajni. Mogućnost preuzimanja zapisa iz biblioteka iz sistema COBISS.MK i iz cijele mreže COBISS.Net omogućila je uštedu i racionalizaciju vremena za obradu bibliotečkog fonda. Ovo je od posebnog značaja za manje biblioteke, one bez licenciranog katalogizatora, koje cijeli svoj fond mogu pronaći već obrađen u sistemu COBISS i jednostavno ga preuzeti u svoju lokalnu bazu podataka. Zatim, velika je ušteda kod pripremanja izlaznih produkata kao što su bibliografije, inventarne knjige, razni spiskovi i statistike. A najveći benefit u odnosu na usluge korisnika je slobodan pristup elektronskim katalozima i mogućnost rezervisanja i pozajmljivanja građe. To je dovelo i do povećanog interesovanja građana za članstvo u bibliotekama i korištenje bibliotečkog fonda. Implementacijom mobilne aplikacije mCOBISS očekujemo da se taj interes korištenja biblioteke i uopšte čitanja knjiga poveća kod mlade populacije. Vidjećemo da li su očekivanja ispravna i realna kada se u sistem COBISS aktivno uključi 5 školskih biblioteka. Potrebno je raditi i na podsticanju postojećih članica na aktivan rad u sistemu i primjenu svih mogućnosti koje pruža programska oprema COBISS. I, naravno, treba produžiti s aktivnostima uključivanja novih biblioteka u sistem COBISS.MK. Nadamo se ne samo da će podršku COBISS-u produžiti resorno ministarstvo kulture već da će razvoj sistema COBISS.MK ponovo (i kontinuirano) podržati i ministarstvo obrazovanja i nauke, s obzirom na to da je sada broj biblioteka obrazovnih i naučnoistraživačkih institucija značajno povećan.

\section{Literatura:}

- Gjalevska, Žaklina. 2005. “Avtomatizacija knjižnic v Makedoniji”" Organizacija znanja, 10(4): 235-240 - ISSN 1580-9803. https://www.cobiss.si/oz/HTML/ OZ_2005_4_final/47/index.html. Datum pristupa: $10 . \overline{1} 1.20 \overline{19}$

- COBISS.MK. "Za COBISS. Pokazateli na prirast". http://www.mk.cobiss.net/pokazateli/ Datum pristupa: 04.10.2019.

- COBISS.MK. "Avtori/Istražuvači. E-CRIS". http:// www.mk.cobiss.net/istrazuvaci.htm Datum pristupa: 05.10.2019.

\title{
COBISS IN MACEDONIA: REVIEW OF TWO ANNIVERSARIES
}

\begin{abstract}
This paper provides a brief overview of the COBISS organizational model and software usage in the development of the national library information system in Macedonia over the past 30 years.

The beginnings of COBISS usage have been running since 1989 within the shared cataloguing system in the SNTIJ / BIS project.

Following the breakup of Yugoslavia and the failure of the shared cataloguing system, several Macedonian libraries have again started $t$ use COBISS software due to the need to introduce new technologies and to automate their processes.

In 2004, when a great number of libraries showed interest to use COBISS software, the Ministry of Culture of RM has decided to use the COBISS platform for the development of the national library information system of Macedonia, and for this purpose, in the National and University Library "Sv. Kliment Ohridski " has established centre of the Virtual Library of Macedonia, i.e. VLM Centre.

For the past 15 years, COBISS.MK has been operating and evolving according to COBISS. Net development plans. By the end of this anniversary year, more than 70 libraries (national, public, higher education and special) will be included in the system. The decades-long implementation of COBISS has made it possible for online libraries to be seen, to save and to organize the time in the process of the library materials cataloguing, and to animate the public by increasing the interest in the use of libraries.
\end{abstract}

Keywords: COBISS.MK, VLM Centre, national library information system of Macedonia, library automation, COBISS.Net, E-CRIS.MK 